\title{
Flexural Behavior of Reinforced High-Performance Concrete Beams Made with Steel Slag Coarse Aggregate
}

\author{
Saaid I. Zaki, Ibrahim M. Metwally, and Sameh A. El-Betar \\ Concrete Structures Research Institute, Housing \& Building National Research Center, \\ 87 El-Tahrir Street, Dokki, P.O. Box 1770, Giza 11511, Egypt \\ Correspondence should be addressed to Ibrahim M. Metwally, dr_ibrahimmetwally@yahoo.com
}

Received 17 July 2011; Accepted 11 August 2011

Academic Editors: M. Maslehuddin and S. Pantazopoulou

Copyright ( $(2011$ Saaid I. Zaki et al. This is an open access article distributed under the Creative Commons Attribution License, which permits unrestricted use, distribution, and reproduction in any medium, provided the original work is properly cited.

In recent years, an emerging technology termed high-performance concrete (HPC) has become popular in construction industry. The constituent materials of HPC depend on the desired characteristics and the availability of suitable local economic alternatives. One of these alternatives is steel slag waste material. It is an industrial by-product waste particles resulted from reinforcing steel bars manufacture, its production is very huge; total quantity produced from all steel rebars manufacture factories in Egypt is nearly million tons/year. HPC made with steel slag aggregate (SSA) is considered as green concrete, using of steel-slag as a coarse aggregate increases the probability of consuming such large accumulations of slag (in HPC industry) which they represent as a waste and polluted material in environment. A total of eight under, balanced and over reinforced concrete beams were fabricated and tested. RC beams were made with HPC having compressive strength of 58.1 and $75.6 \mathrm{MPa}$ and tensile reinforcement ratio in the range of 0.90 to $4.3 \%$. Data presented concentrated on the chemical, physical, and mechanical properties of the used new material (SSA) and the flexural behavior of reinforced high-performance concrete beams made with steel slag coarse aggregate (RHPC-SSA) beams. It was observed that the RHPC-SSA beams can give satisfactory structural performance according to the American and Egyptian Building Codes.

\section{Introduction}

With evergrowing population and with expanding urban centers, increased levels of construction are expected in the forthcoming years in Egypt as a developing country. Due to enhanced mechanical properties and durability, highperformance concrete (HPC) has gained wider acceptance in the construction of tall buildings, bridges, and marine structures. Aitcin [1] defines HPC as a low water/binder concrete with an optimized aggregate-to-binder ratio to control its dimensional stability (i.e., drying shrinkage) and which receives an adequate water curing (to control autogenous shrinkage). Although HPC has found widespread application, its production is still limited in many countries because suitable concrete aggregate such as river sand, gravel or hard crushed aggregates are either not available or are available only in limited quantity. Due to environmental impacts associated with aggregate extraction, considerable efforts have been made towards the utilization of indigenous and waste materials (byproducts) in concrete. The main advantages of the use of byproducts from the various origins in the production of concrete are the elimination of scraps, and a reduction in the overexploitation of quarries. As a result, the use of the following byproducts has been proposed as aggregate for concrete: construction rubber, vitrified flooring, glass, plastic, the remains of asphalt agglomerates and metallurgical or steel making slag [2]. All of these byproducts, as well as others not mentioned, have been tested with varying degrees of success. However, the most promising proposal is the use of iron and steel slag due to the qualities of this material.

There are several kinds of slag obtained after the different processes of steel-making (blast furnace slag, basic oxygen furnace slag, electric arc furnace slag,...) with different characteristics [3]. Our study focuses only on the use of electric arc furnace slag which obtained as byproduct particles from steel bars manufacture as a coarse aggregate to produce high-performance concrete. Steel slag aggregate 
(SSA) is considered as an alternative coarse aggregate; it is available locally in large quantity, and produced in amount of 150 tons/day in the Al Ezz Steel Rebar Factory in Sadat City, Egypt. The total production of SSA in all steel rebars manufacture factories in Egypt is nearly million tons/year. The present paper succeeded to introduce a solution to consume the huge production of this waste in the production of green concrete with high performance made with SSA.

It is well established and commonly accepted that the properties of an aggregate used in HPC have great influence on structural properties and on durability [4, 5]. Most of the studies on flexural behavior of beams with high-strength concrete are reported using river sand and hard dense coarse aggregate (traditional aggregates) [6-9]. Hence, this paper reports the results of an experimental investigation on the effect of using steel slag as coarse aggregate on flexural behavior of simply supported reinforced HPC beams.

\section{Research Significance}

At present time, approximately no papers and data about utilization of SSA in reinforced concrete elements are available. This investigation provides satisfactory experimental data and examines the applicability of the ACI 318-08 [10] and ECP 203-07 [11] Building Codes provisions for predicting the strength and flexural behavior of reinforcedHPC beams made with SSA. Reinforced concrete members made with SSA are able to fulfill comparable strength and serviceability requirements as conventional RC members. It is demonstrated that the flexural performance of reinforcedHPC beams made with SSA can be equal or even superior to that of similar beams made of conventional aggregates.

\section{Experimental Program}

\subsection{Materials}

3.1.1. Ordinary Portland Cement (OPC). OPC was obtained from the Suez Cement Factory of grade 52.5; the used cement complies with the ASTM Standard Specifications.

3.1.2. Silica Fume (SF). SF was a very fine byproduct powder obtained as a fume from the foundry process in the Egyptian company for iron foundries.

3.1.3. Coarse Aggregate (CA). CA used in this paper was steel slag aggregate (SSA) and dolomite aggregate (DA), while fine aggregate was natural sand obtained from pyramids quarry in Egypt; the used aggregate complies with ASTM Specifications.

3.1.4. Steel Slag Aggregate (SSA). SSA used in this paper is an industrial byproduct obtained from Al Ezz Steel Rebars Factory (Sadat City, Egypt) with nominal max. size equal $20 \mathrm{~mm}$; it is produced in large quantities 150 tons/day during the steel manufacture operation using electric arc furnace; it was exposed to air currents to cool giving porous slag particles.

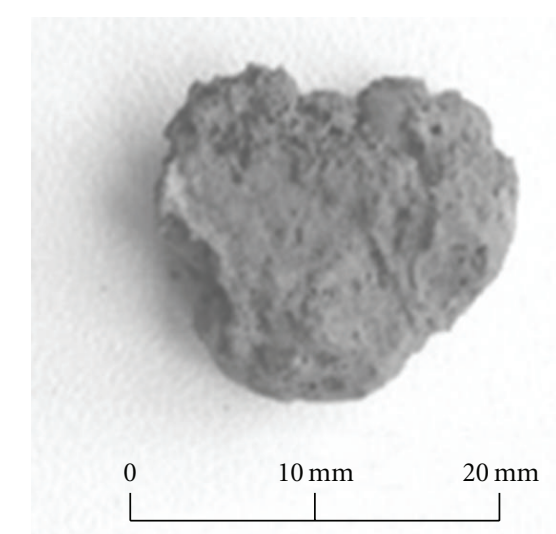

FIgURE 1: Appearance of electric arc furnace slag [3].

TABLE 1: Chemical composition of SSA.

\begin{tabular}{lc}
\hline Constituent & Composition, \% \\
\hline $\mathrm{SiO}_{2}$ & 29.3 \\
$\mathrm{Al}_{2} \mathrm{O}_{3}$ & 3.16 \\
$\mathrm{Fe}_{2} \mathrm{O}_{3}$ & 26.48 \\
$\mathrm{CaO}$ & 33.2 \\
$\mathrm{MgO}$ & 6.4 \\
$\mathrm{SO}_{3}$ & 0.71 \\
$\mathrm{LOI}$ & 0.49 \\
$\mathrm{Na}_{2} \mathrm{O}$ & 0.09 \\
$\mathrm{~K}_{2} \mathrm{O}$ & 0.04 \\
$\mathrm{CL}$ & 0.02 \\
\hline
\end{tabular}

TABle 2: Physical and mechanical properties of steel slag and dolomite aggregates.

\begin{tabular}{lcc}
\hline Coarse aggregate type & SSA & DA \\
\hline Physical Properties & & \\
\hline Unit weight, $\mathrm{kg} / \mathrm{m}^{3}$ & 1970 & 1570 \\
Specific weight & 3.63 & 2.55 \\
Water absorption, \% & 1 & 1.7 \\
\hline Mechanical properties & & 13 \\
\hline Impact, \% & 10 & 18 \\
Abrasion, \% (Los Angeles) & 13.5 & 17 \\
Crushing, \% & 12 &
\end{tabular}

Figure 1 shows the appearance of the slag samples in the coarse aggregate size underlining its rough or cavernous surface texture and its rounded shape.

The chemical properties of steel slag aggregate are shown also in Table 1.

3.1.5. Dolomite Aggregate (DA). DA used in this paper was of nominal max. size equal $20 \mathrm{~mm}$ which was obtained from the Attaka quarry in Egypt. The physical and mechanical properties of SSA and DA are shown in Table 2. 


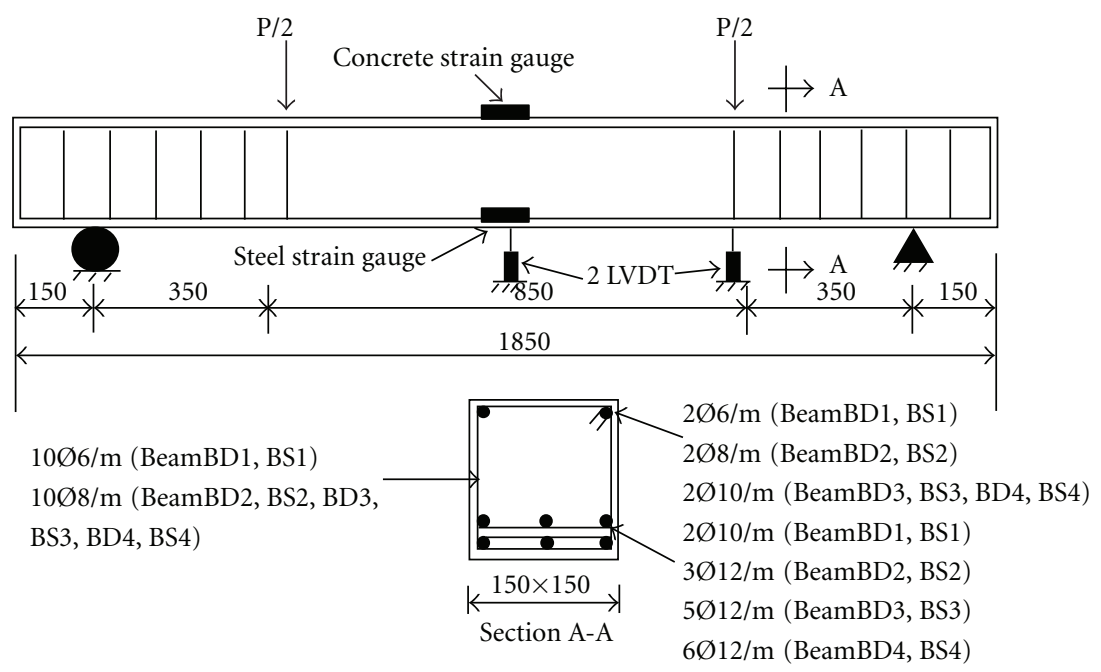

FIGURE 2: Testing setup, beam details, and typical reinforcement arrangement for the test beams (all dimensions in mms).

3.2. Admixture. Polycarboxylate-based superplasticizer (Glenium Sky 510) was used for all concrete mixes to improve the workability.

3.3. Steel Reinforcement. Deformed high-grade steel bars of about $400 \mathrm{MPa}$ yield strength and of 10 and $12 \mathrm{~mm}$ diameters was used as longitudinal tensile reinforcement. The stirrups used were made of 6 and $8 \mathrm{~mm}$ diameters smooth bars of 351.2 MPa yield strength.

3.4. Concrete Mix Design. The concrete mixtures were prepared with SSA and DA and designed according to ACI 211.1-91 [11] as shown in Table 3.

3.5. Reinforced Concrete Beam Details. Eight reinforced highperformance concrete beams were cast. All beams have the same concrete dimensions $(150 \times 150 \times 1850 \mathrm{~mm})$. The beams had no shear reinforcement (stirrups) in the flexural zone. But the shear zone which had length equal $350 \mathrm{~mm}$ was confined by closed stirrups at every $100 \mathrm{~mm}$. The tested beams were classified into two groups (each one consists of four beams) according to coarse aggregate type. First group of beams are control made with the dolomite aggregate. The second one was designed to study the effect of utilizing steel slag as coarse aggregate on the flexural behavior of HPC beams. Each beam was designated using letters and numbers. The letter " $\mathrm{B}$ " refers to the type of structural element used, here is a beam. The letters " $D$ " and "S" refer to the dolomite and steel slag, respectively. The numbers $(1,2,3$, and 4$)$ refer to the percentage of tension reinforcement ratio $(0.9 \%, 1.95 \%, 3.6 \%$, and $4.3 \%$, resp.). Typical reinforcement arrangement and geometry of the beam are shown in Figure 2 and Table 4.

3.6. Beam Instrumentation and Testing. The tested beams were simply supported over two rigid supports as shown in Figure 3. Two-point loads were applied to all the beams

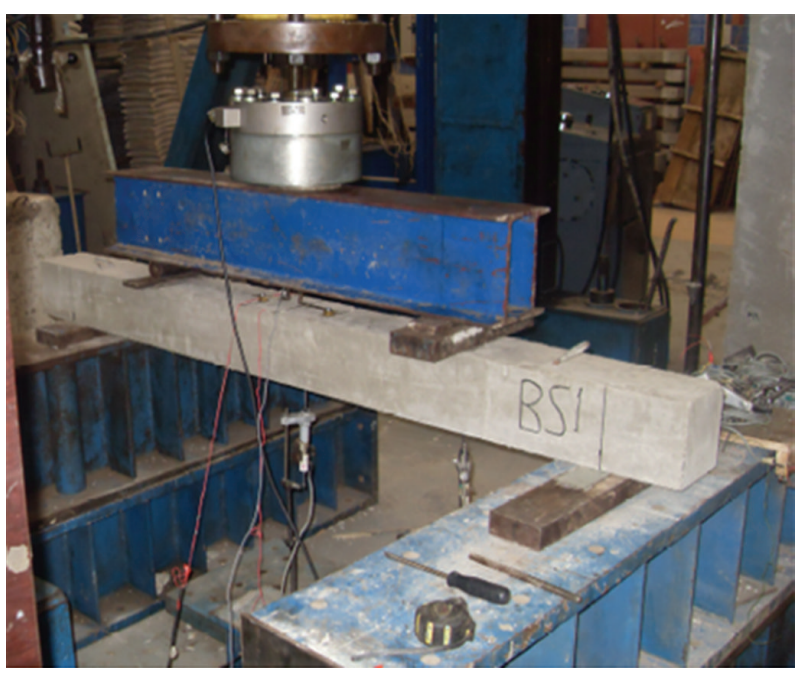

Figure 3: Setup of RC beams.

and were monotonically increased until failure. The load was applied vertically at the center of rigid steel beam which transmitted the load equally on two bearings rested on the beam top, spaced $850 \mathrm{~mm}$, and aligned symmetrically around the beam centerline. The deflections were measured at the mid span and under one loading point by using $\pm 200 \mathrm{~mm}$ linear variable differential transducers (LVDTs). On the top surface of the beams in the central region, bi-gauges with a length of $200 \mathrm{~mm}$ were attached to measure the compressive concrete strains in the pure bending region. Strain at the centre of the longitudinal tension reinforcing bars was measured using electrical strain gauges, which were attached to the surface of tension reinforcement to check the yielding of this reinforcement. The measured data were recorded by a data logger connected to computer system programmed using lab view software. 
TABLE 3: Mix proportion of ingredients.

\begin{tabular}{|c|c|c|c|c|c|c|}
\hline \multirow{2}{*}{ Type of mix } & \multicolumn{6}{|c|}{ Mix proportions $(\mathrm{Kg})$ for $1.0 \mathrm{~m}^{3}$} \\
\hline & Cement & Silica fume & C. Agg. & F. Agg. & Water & Add. \\
\hline Steel slag agg. mix & 500 & 75 & 1000 & 750 & 201 & 8.5 \\
\hline Dolomite agg. mix & 500 & 75 & 1000 & 750 & 201 & 8.5 \\
\hline
\end{tabular}

TABLE 4: Characteristics of the beams.

\begin{tabular}{lccccc}
\hline Beam & $f_{\text {cu }} \mathrm{MPa}$ & $d, \mathrm{~mm}$ & $b, \mathrm{~mm}$ & $A_{s}, \mathrm{~mm}^{2}$ & 157 \\
BD1 & & 116.3 & 150 & 339 & 0.90 \\
BD2 & 58.1 & 116 & 150 & 565 & 1.95 \\
BD3 & & 105 & 150 & 679 & 3.6 \\
BD4 & & 105 & 150 & 157 & 4.3 \\
\hline BS1 & 116.3 & 150 & 339 & 0.90 \\
BS2 & 116 & 150 & 565 & 3.9 \\
BS3 & 75.6 & 105 & 150 & 679 & 4.3 \\
BS4 & & 105 & 150 & & \\
\hline
\end{tabular}

\section{Results: Analysis and Discussion}

\subsection{Aggregate Properties}

4.1.1. Physical and Mechanical Properties. The physical properties of SSA are superior to those of DA except for the specific weight; Table 2 shows that the specific weight of SSA is 3.63 while it is 2.55 for the DA; also the unit weight of SSA is $1970 \mathrm{~kg} / \mathrm{m}^{3}$, while it is $1570 \mathrm{~kg} / \mathrm{m}^{3}$ for DA.

The water absorption for SSA is $1 \%$, while it was $1.7 \%$ for DA; the reduction in absorption characteristics of SSA can be attributed to the impervious nature of SSA compared with DA, which can lead to more impermeable concrete when SSA is used.

Steel slag has favorable mechanical properties for use as coarse aggregate in construction; these include good abrasion resistance, good impact, and crushing values as compared with DA as shown from Table 3.

4.1.2. HPC Properties. Table 5 shows the structural properties such as compressive strength $\left(f_{\mathrm{cu}}\right)$, splitting tensile strength $\left(f_{t}\right)$, and static modulus of elasticity $\left(E_{c}\right)$ of the companion HPC. Specimens were tested at the same testing age of beams.

From Table 5, it can be noticed that using of SSA with HPC enhances clearly the mechanical properties as $f_{\mathrm{cu}}, f_{t}$, and $E_{c}$ compared with dolomite aggregate concrete; it is attributed to the superior physical and mechanical properties of SSA as shown in Table 2.

\subsection{Flexural Behavior of RHPC Beams}

4.2.1. Failure Modes. After failure, all beams showed typical structural behavior in flexure, no horizontal cracks were observed at the level of the reinforcement, which indicated that there were no occurrences of bond failure. For under - and balanced reinforced concrete beams, the longitudinal tension steel yielded first, followed by the concrete crushing,

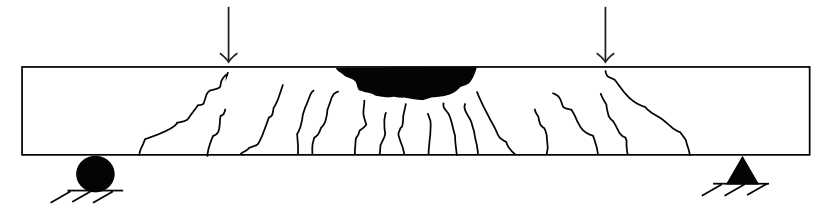

(a) Tension Failure

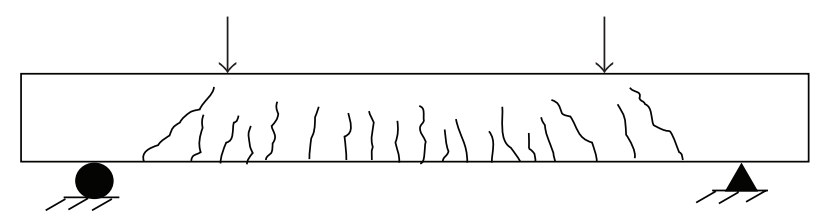

(b) Compression Failure

FIgURE 4: The two governed modes of failure.

which is a ductile mode of failure, normally called tension failure. For overreinforced beams, the concrete reached its maximum capacity first, followed shortly by the yielding of the longitudinal tensile reinforcements and the final failure of the beam. This mode of failure, termed compression failure, was relatively brittle. Figure 4 illustrates the typical crack patterns of the two governed flexural modes of failure. These modes of failure are well established for conventional reinforced concrete beams; and based on the current results, the flexural behavior of reinforced steel slag concrete beams is not affected by the presence of steel slag as a coarse aggregate in concrete. This is true for both under - and overreinforced beams. Any differences that were observed were minor with no practical significance.

4.2.2. Design and Ultimate Moments. The design moment at service loads calculated by working-stress design method [12], together with the experimental and calculated ultimate flexural moments, are shown in Table 6. 
TABLE 5: 28-Day test results of HPC, MPa.

\begin{tabular}{lccc}
\hline Type of mix & $\begin{array}{c}\text { Compressive strength } \\
\text { " } f_{\mathrm{cu}} \text { " }\end{array}$ & $\begin{array}{c}\text { Splitting tensile strength } \\
\text { " } f_{t} "\end{array}$ & $\begin{array}{c}\text { Static modulus of elasticity } \\
\text { " } E_{c} ”\end{array}$ \\
\hline Steel slag agg. mix & 75.6 & 21 & 38000 \\
Dolomite agg. mix & 58.1 & 11 & 33000 \\
\hline
\end{tabular}

The calculated ultimate moments are based on ACI 318 [10] and ECP 203 [11] (rectangular stress block) Codes without, of course, the safety factors.

The results show that, at failure, the beams had load factors ranging from 2.82 to 4.53 against (1.2 and 1.6) and (1.4 and 1.6) for dead and imposed loads incorporated in design as reported in ACI 318 and ECP 203 Codes, respectively.

The average ratio of experimental ultimate moment to the ACI 318 predicted ultimate moment was found to be 1.55 (except BD1 and BS1), and this was almost identical to the ratios based on the ECP 203 Code. Both codes are more conservative, it is interesting to note that both codes predict almost the same ultimate moment capacity and that there is practically no difference in the two predicted moments between the two approaches. The results of Table 6 confirm that the design in flexure of concrete beams made with steel slag coarse aggregate and sand, according to the American and Egyptian Building Codes, will provide an adequate load factor against failure.

4.3. Cracking Moment. Table 7 shows the observed moments

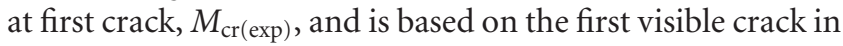
the pure bending region. The predicted cracking moments,

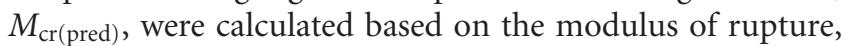
$f_{r}$, using Clause 9.5.2.3 of ACI 318 [10] or ECP 203 [11] provisions; the two codes are the same:

$$
M_{\mathrm{cr}}=\frac{f_{r} I_{g}}{y_{t}} \mathrm{~N} \cdot \mathrm{mm}, \quad f_{r}=0.7 \sqrt{f_{c}^{\prime}} \mathrm{MPa},
$$

where $I_{g}$ : gross moment of inertia, $y_{t}$ : distance between NA and extreme tension fiber.

The obtained ratio of the $M_{\mathrm{cr}(\exp )}$ to the corresponding $M_{\text {cr(pred) }}$ was varied from 1.16 to 2.33. Koyangi et al. [13] demonstrated that the concrete using reactive slag aggregate with tensile reinforcement ratio exceeding $2 \%$ experienced nearly twice the cracking loads of unaffected concrete. This may be due to the internal restraint caused by the tensile reinforcement in the RC beams. Probably this may be the reason for variation in cracking moment. However, more data on flexural behavior using steel slag aggregate are needed to clarify this discussion.

4.4. Ductility Behavior. Ductility is the measure of the element capacity to undergo inelastic behavior and absorb energy. Several forms of ductility are available. These include curvature, rotational, and displacement ductility. In this research, displacement ductility is investigated. Displacement ductility, $\mu_{d}$, is defined as the ratio of deflection at

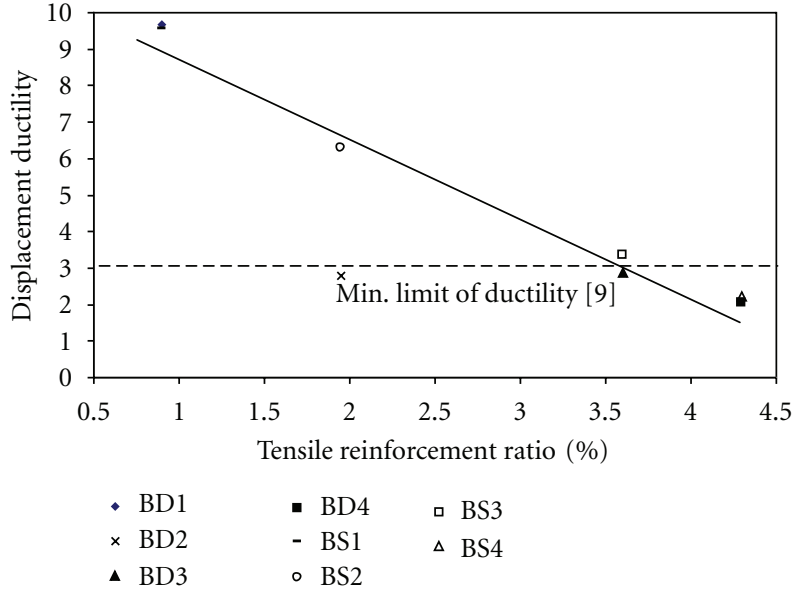

Figure 5: Ductility versus tensile reinforcement ratio.

ultimate moment to the deflection at first yielding of the tensile reinforcement [12].

In general, high ductility ratios indicate that a structural member is capable of undergoing large deflections prior to failure.

From Table 8 and Figure 5, it was observed that steel slag aggregate improved the ductility of RC beams clearly compared to dolomite concrete beams at all reinforcement ratios. It was noticed also that, for beams with $\rho$ up to $3.6 \%$, the ductility ratio was more than 3 , which shows relatively good ductility. One of the factors contributing to the good ductility behavior of the steel slag concrete beams was the toughness and the good shock absorbance nature of the SSA as indicted by the aggregate crushing value and aggregate impact value from Table 2. Ashour [9] mentions that the displacement ductility, $\mu_{d}$, in the range of 3 to 5 is considered imperative for adequate ductility, especially in the areas of seismic design and the redistribution of moments. Therefore, assuming that a $\mu_{d}$ value of 3 represents an acceptance lower bound to ensuring the ductile behavior of flexural members.

From this study, it was also observed that a higher tension-reinforcement ratio results in less ductile behavior. This is in agreement with the work of other researches [6-9].

4.5. Neutral Axis Depth. Neutral axis (NA) depth was obtained from the strain distribution, which was measured experimentally at the compression concrete and at the tension reinforcement. The $x_{\text {theo }} / d$ (neutral axis-to-depth ratio) predicted based on the rectangular stress block given in ECP 203 [11], and, for the ratio $x_{\exp } / d$ to $x_{\max } / d$, the value of 0.50 was taken as $x_{\max } / d$ (limiting value recommended 
TABLE 6: Experimental and calculated moments.

\begin{tabular}{|c|c|c|c|c|c|c|c|}
\hline \multirow[t]{2}{*}{ Beam } & \multirow[t]{2}{*}{$f_{\mathrm{cu}} \mathrm{MPa}$} & \multirow[t]{2}{*}{$f_{c}^{\prime} \mathrm{MPa}$} & \multirow[t]{2}{*}{$\begin{array}{l}\text { Calculated design service } \\
\text { moment } M \mathrm{kN} \cdot \mathrm{m}\end{array}$} & \multirow[t]{2}{*}{$\begin{array}{l}\text { Experimental ultimate } \\
\text { moment } M_{\text {uexp }} \mathrm{kN} \cdot \mathrm{m}\end{array}$} & \multicolumn{2}{|c|}{$\begin{array}{c}\text { Capacity ratio of beams } \\
\qquad M_{\text {uexp }} / M_{\text {upred }}\end{array}$} & \multirow[t]{2}{*}{$\begin{array}{l}\text { Load factor } \\
M_{\text {uexp }} / M\end{array}$} \\
\hline & & & & & ACI 318 & ECP 203 & \\
\hline BD1 & \multirow{4}{*}{58.1} & \multirow{4}{*}{46.5} & 3.25 & 14.72 & 2.11 & 2.11 & 4.53 \\
\hline BD2 & & & 7 & 21.18 & 1.49 & 1.5 & 3.03 \\
\hline BD3 & & & 10.55 & 32.08 & 1.65 & 1.66 & 3.04 \\
\hline BD4 & & & 12.68 & 35.75 & 1.60 & 1.61 & 2.82 \\
\hline BS1 & \multirow{4}{*}{75.6} & \multirow{4}{*}{60.5} & 3.19 & 14 & 1.98 & 1.99 & 4.4 \\
\hline BS2 & & & 6.87 & 22.85 & 1.57 & 1.57 & 3.33 \\
\hline BS3 & & & 10.37 & 29.51 & 1.45 & 1.45 & 2.85 \\
\hline BS4 & & & 12.46 & 37.12 & 1.56 & 1.57 & 3 \\
\hline
\end{tabular}

TABLe 7: Experimental and calculated cracking moment.

\begin{tabular}{|c|c|c|c|c|c|}
\hline \multirow{2}{*}{ Beam } & \multirow{2}{*}{$f_{\text {cu }} \mathrm{MPa}$} & \multirow{2}{*}{$f_{c}^{\prime} \mathrm{MPa}$} & \multicolumn{2}{|c|}{ Cracking moment $\left(M_{\mathrm{cr}}\right) \mathrm{kN} \cdot \mathrm{m}$} & \multirow{2}{*}{$M_{\mathrm{cr}(\exp )} / M_{\mathrm{cr}(\text { pred })}$} \\
\hline & & & $M_{\mathrm{cr}(\exp )}$ & $M_{\mathrm{cr}(\mathrm{pred})}$ & \\
\hline BD1 & \multirow{4}{*}{58.1} & \multirow{4}{*}{46.5} & 3.65 & 2.57 & 1.42 \\
\hline $\mathrm{BD} 2$ & & & 4.2 & 2.57 & 1.63 \\
\hline BD3 & & & 5.15 & 2.57 & 2 \\
\hline BD4 & & & 6 & 2.57 & 2.33 \\
\hline BS1 & \multirow{4}{*}{75.6} & \multirow{4}{*}{60.5} & 3.4 & 2.93 & 1.16 \\
\hline BS2 & & & 3.6 & 2.93 & 1.23 \\
\hline BS3 & & & 4.1 & 2.93 & 1.4 \\
\hline BS4 & & & 5.2 & 2.93 & 1.77 \\
\hline
\end{tabular}

in ACI 318 [10] and ECP 203 [11] at ultimate limit state). The test results are analyzed and presented in Table 8 . It was shown from test results that, for a given concrete strength, the NA depth (experimental or theoretical) increases as tensile reinforcement ratio increases for both dolomite concrete beams and steel slag concrete beams. A lower reinforcement ratio ensures that the depth of NA is lower, hence, leading to ductile failure. The NA moves closer to the top of fiber with the increase in strength. This trend is similar to other reported studies (Figure 6) for high-strength concrete beams with compressive strengths in the range from 60 to $130 \mathrm{MPa}$ made with other aggregates $[9,14,15]$.

It was noted from analysis that, for the design of flexural members, in high-strength concrete (HSC) the limit on the allowable $x_{\max } / d$ suggested in ACI 318 [10] and ECP 203 [11] codes is conservative. The ultimate concrete strain is assumed as 0.003 , and it used for calculating the NA depth. But for HSC, the max. depth of NA is a function of concrete strength and ultimate concrete strain. It was shown by many researchers that the ultimate concrete strain of HSC varies from 0.002 to 0.004 or even more. Therefore, it is necessary to revise rectangular stress-strain parameters to integrate the concrete strength as a function to evaluate ultimate concrete strain.

4.6. Evolution of the Neutral Axis Depth with Ductility. This section deals with the evolution of the NA depth characterized by parameter $x_{\exp } / d$, with the ductility indices

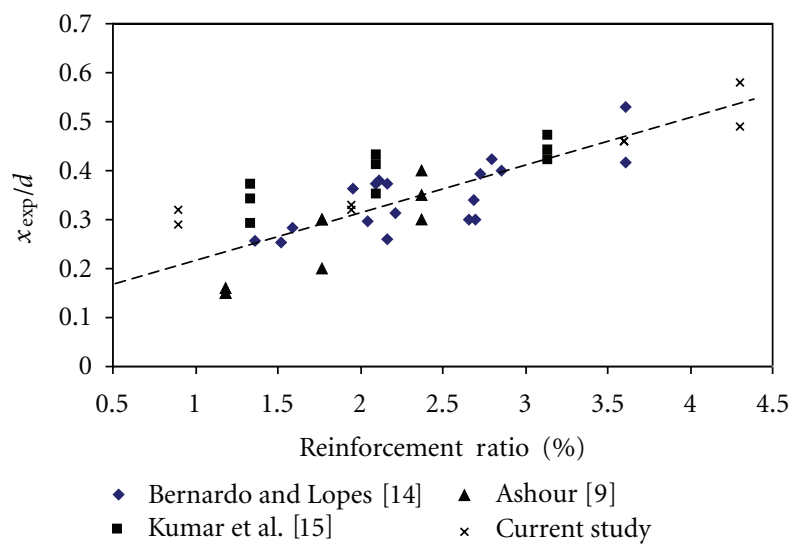

Figure 6: Neutral axis depth versus tensile reinforcement ratio.

experimentally recorded from the tested beams at failure (see Table 8). Figure 7 present the graph relationship of the NA depth values defined through parameter $x_{\exp } / d$, with the displacement ductility index, $\mu_{d}$. Its trend seems to show that, as the NA depth at failure increases, the beam's ductility decreases for both dolomite concrete beams and steel slag concrete beams, this agrees with $[9,14,15]$, as shown in Figure 7.

Therefore, the experimental results confirm the validity of the design rule used for normal-strength concrete that ensures an adequate ductility level by limiting the NA depth 
TABLe 8: Displacement ductility, $x / d$ ratio, and strain values for the tested beams.

\begin{tabular}{|c|c|c|c|c|c|c|c|c|}
\hline Beam & $\rho, \%$ & $\mu_{d}$ & $\frac{x_{\exp }}{d}$ & $\frac{x_{\text {theo }}}{d}$ & $\frac{x_{\exp } / d}{x_{\text {theo }} / d}$ & $\frac{x_{\exp } / d}{x_{\max } / d}$ & $\begin{array}{c}{ }^{*} \text { Concrete compressive } \\
\text { strain }\end{array}$ & $\begin{array}{c}{ }^{*} \text { Tensile steel } \\
\text { strain }\end{array}$ \\
\hline BD1 & 0.90 & 9.66 & 0.29 & 0.34 & 0.85 & 0.58 & 0.0044 & 0.0107 \\
\hline BD2 & 1.95 & 2.8 & 0.32 & 0.46 & 0.70 & 0.64 & 0.0018 & 0.0038 \\
\hline BD3 & 3.6 & 2.89 & 0.46 & 0.56 & 0.82 & 0.92 & 0.002 & 0.0023 \\
\hline BD4 & 4.3 & 2.04 & 0.49 & 0.59 & 0.83 & 0.98 & 0.0017 & 0.0018 \\
\hline BS1 & 0.90 & 9.55 & 0.32 & 0.34 & 0.94 & 0.64 & 0.0049 & 0.0106 \\
\hline BS2 & 1.95 & 6.29 & 0.33 & 0.46 & 0.72 & 0.66 & 0.0052 & 0.0106 \\
\hline BS3 & 3.6 & 3.34 & 0.46 & 0.56 & 0.82 & 0.92 & 0.0025 & 0.0029 \\
\hline BS4 & 4.3 & 2.22 & 0.58 & 0.59 & 0.98 & 1.16 & 0.0028 & 0.002 \\
\hline
\end{tabular}

${ }^{*}$ Tabulated concrete and steel strains were recorded approximately at $85 \%$ of the ultimate moment.

TABLE 9: Experimental and predicted deflection at service moment.

\begin{tabular}{|c|c|c|c|c|c|}
\hline Beam code & $\begin{array}{l}\text { Calculated design service } \\
\text { moment } M \mathrm{kN} \cdot \mathrm{m}\end{array}$ & $\begin{array}{l}\text { Exp. deflection at } M \text { from } \\
\text { test, } \mathrm{mm}\end{array}$ & $\begin{array}{c}\text { Calculated deflection at } M \text {, } \\
\text { mm } \\
\text { ACI } 318 \text { or ECP } 203\end{array}$ & Exp. def/cal. def & Span/exp. def. \\
\hline $\mathrm{BD} 1$ & 3.25 & 1.50 & 1.02 & 1.47 & 1033 \\
\hline BD2 & 7 & 3 & 2.70 & 1.11 & 517 \\
\hline BD3 & 10.55 & 3.94 & 3.97 & 0.99 & 393 \\
\hline BD4 & 12.68 & 3.4 & 4.37 & 0.78 & 456 \\
\hline BS1 & 3.19 & 2 & 0.66 & 3.02 & 775 \\
\hline BS2 & 6.87 & 3.6 & 2.24 & 1.60 & 430 \\
\hline BS3 & 10.37 & 3.9 & 3.37 & 1.16 & 397 \\
\hline BS4 & 12.46 & 3.36 & 3.72 & 0.90 & 461 \\
\hline
\end{tabular}

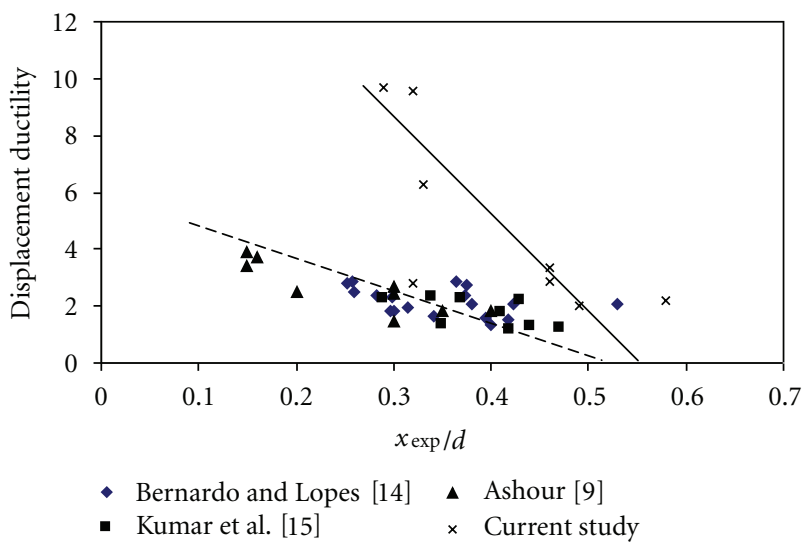

FIgURE 7: Ductility versus neutral axis depth.

for the studied section. This rule seems to be also valid for high performance concrete beams containing steel slag as coarse aggregates.

4.7. Concrete and Steel Strains. The concrete and steel strains at midspan of the beam (at top extreme fiber and tensile reinforcement for concrete and steel, resp.) were recorded through all loading stages until failure. At ultimate loading stage, the measurement of strains may not be precise because of rapid advancement of cracks. Therefore, the results in Table 8 show the concrete and steel strains at approximately $85 \%$ of the ultimate moment. Therefore, the strains, before final failure, may have been higher than the strains mentioned here.

The recorded strains were in the range of 0.0017 to 0.0052 and 0.0018 to 0.0107 for concrete and tensile steel, respectively. From the data in Table 8 , it is noticed that no big difference between the strains for both RC beams with dolomite and the others with steel slag as a coarse aggregate. The recorded values of strains of steel slag concrete beams (especially, BS1 and BS2) were relatively higher when compared with the other high-strength concrete beams containing traditional coarse aggregate $[9,14-16]$. The higher steel strains also show that good bond between steel bars and concrete existed till the yielding of steel.

4.8. Deflection Behavior. Figure 8 shows the typical experimental moment-deflection curves for all studied beams. In all beams, before cracking, the slope of the curves was steep and closely linear. Once flexural cracks formed, a change the in slope of the curve was observed, and this slope remained fairly linear until yielding of the steel reinforcement took place. From the moment deflection curves, it can be observed that steel slag concrete beams exhibit behavior nearly similar to that of control beams and other high-strength concrete beams containing traditional coarse aggregate $[9,14-16]$. The observed experimental midspan deflection under service moment was compared with deflection evaluated from ACI 318 or ECP 203 (both codes are similar) as shown in Table 9. 


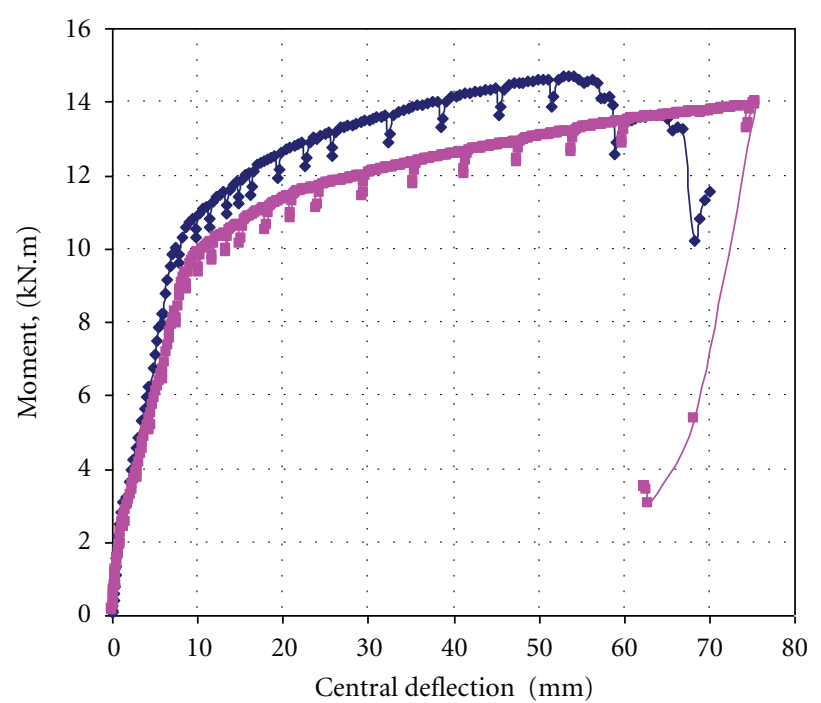

$\mathrm{BD} 1$ and BS1

$$
\begin{array}{ll}
\longrightarrow & \text { BD1 } \\
\longrightarrow & \text { BS1 }
\end{array}
$$

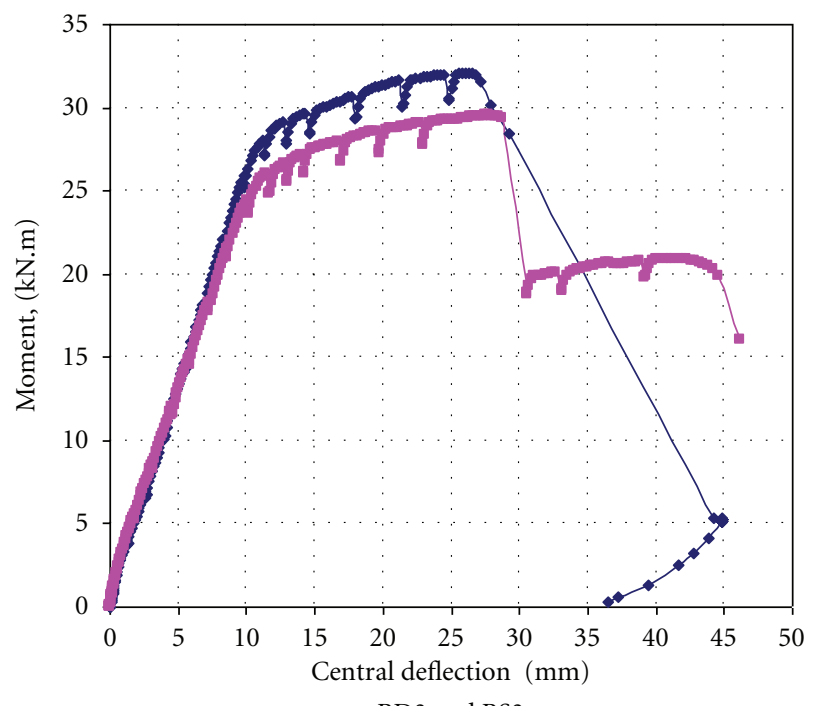

BD3 and BS3

$$
\rightarrow \mathrm{BD} 3
$$

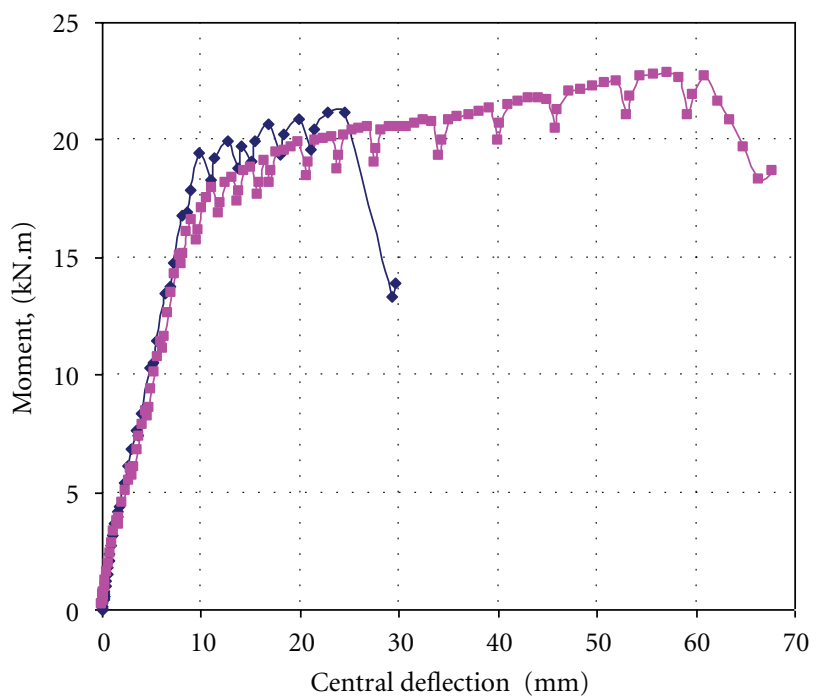

$\mathrm{BD} 2$ and $\mathrm{BS} 2$

$$
\rightarrow \mathrm{BD} 2
$$$$
\rightarrow \mathrm{BS} 2
$$

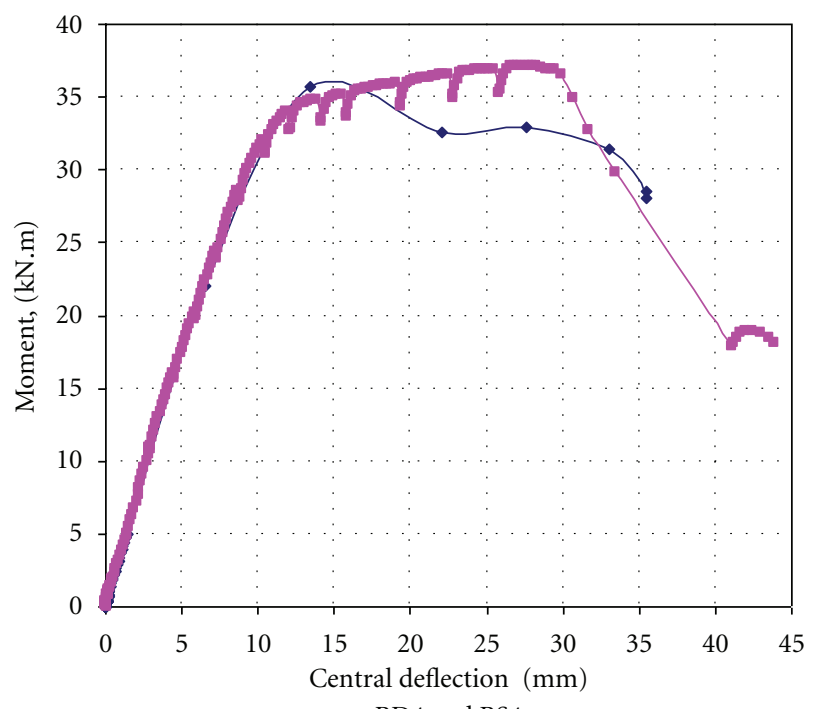

BD4 and BS4

$$
\begin{aligned}
& \longrightarrow \mathrm{BD} 4 \\
& \longrightarrow \mathrm{BS} 4
\end{aligned}
$$

FIgURE 8: Experimental moment-deflection curves for all beams.

The service moments were calculated by the working-stress design method [12]. From Table 9, it was found that the values of experimental deflection for both dolomite concrete beams and steel slag concrete beams are nearly the same. The average ratio of measured deflection to the predicted deflection was found to be 1.14 (except BS1) based on ACI 318 or ECP 203. From the analysis, it was found that there is nearly a close agreement between predicted and experimental deflections.

The modulus of elasticity of concrete is very much governed by the stiffness of the coarse aggregate. From the properties in Tables 2 and 5, it can be seen that the stiffness of steel slag aggregate is higher than dolomite, leading to higher $E_{c}$ of steel slag concrete, resulted in limiting of deflections. The deflection under the design service moments for all studied beams is acceptable as the span deflection ratios ranged between 393 to 1033 and are within the allowable limit provided by ACI 318 and ECP 203. They recommend an upper limit of span/250 for the deflection in order to satisfy the appearance and safety criteria of a structure. However, these measured deflections were based on short-term loading (not taking into account creep effects). However, it must be noted that, in order to obtain a complete understanding of the deflection behavior, further investigations incorporating 
the effects of shrinkage and creep on the concrete are required.

\section{Conclusions}

From the experimental investigation, it was generally observed that the flexural behavior of steel slag concrete is comparable to that of other types of natural aggregate concretes, and this investigation gives encouraging results for steel slag to be used as coarse aggregate in the production of structural concrete especially for the construction of lowcost houses because the steel slag particles are very cheap compared to the other traditional coarse aggregates. The following observations and conclusions can be made on the basis of the current experimental results.

(1) HPC-containing steel slag coarse aggregate attained superimprovement in mechanical properties (compressive strength, tensile strength, and static modulus of elasticity) compared with dolomite aggregate concrete. It can be said that this research work succeeded to introduce a solution to consume the huge production of the steel slag waste in the production of green concrete with high performance.

(2) Both steel slag concrete beams and dolomite concrete beams showed typical structural behavior in flexure. At both the service and ultimate states, the flexural performance of reinforced steel slag concrete beams can be comparable or even superior to that of concrete made entirely with natural aggregates.

(3) ACI 318 and ECP 203 Codes can be used to obtain a conservative estimate of the ultimate moment capacity and also provide adequate load factor against failure for all high-performance concrete beams (control and steel slag concrete beams).

(4) The ratio of the experimental cracking moment to the predicted one was found to be 1.16 to 2.33 . This result implies that the internal restraint caused by the tensile reinforcement greatly influenced the cracking load.

(5) Steel slag concrete beams showed good ductility behavior with tension reinforcement ratio up to $3.6 \%$. All beams exhibited considerable amount of deflection, which provided ample warning to the imminence of failure.

(6) The tests of both high-performance concrete beams containing dolomite and steel slag as coarse aggregates reported here indicate that, for concrete strengths approximately equal, the NA depth in failure increases with increasing of tensile reinforcement ratio. It also indicates that as the NA depth in failure increases, the beams' ductility decreases. Therefore, the practical rule of limiting the NA depth on critical sections, to assure adequate ductility levels, seems to be also valid for high-performance concrete beams containing steel slag as a coarse aggregate.
(7) Higher tensile steel strain of the steel slag concrete beams (especially, BS1, BS2) shows the existence of stronger bond between the concrete and the steel reinforcement. In general, it can be reported that the concrete incorporating steel slag coarse aggregate is able to achieve its full strain capacity under flexural loading.

(8) No big difference between the deflection of steel slag concrete beams and dolomite concrete beams at various reinforcement ratios, both are nearly same.

(9) The deflection of steel slag concrete beams calculated using ACI 318 or ECP 203 under service loads can be used to give reasonable prediction.

\section{References}

[1] P. C. Aitcin, "The durability characteristics of high performance concrete: a review," Cement and Concrete Composites, vol. 25, no. 4-5, pp. 409-420, 2003.

[2] W. M. Shelburne and D. J. Degroot, "The use of waste and recycled materials in highway construction," Civil Engineering Practice, vol. 13, no. 1, pp. 5-16, 1998.

[3] R. Tomellini, Ed., "Summary report on RTD in iron and steel slags: development and perspectives," Technical Steel Research, Report Prepared for the European Commission EUR 19066, Brussels, Belgium, 1999.

[4] K. R. Wu, B. Chen, W. Yao, and D. Zhang, "Effect of coarse aggregate type on mechanical properties of high-performance concrete," Cement and Concrete Research, vol. 31, no. 10, pp. 1421-1425, 2001.

[5] W. Baalbaki, B. Benmokrane, O. Chaallal, and P. C. Aietcin, "Influence of coarse aggregate on elastic properties of highperformance concrete," ACI Materials Journal, vol. 88, no. 5, pp. 499-503, 1991.

[6] M. A. Rashid and M. A. Mansur, "Reinforced high-strength concrete beams in flexure," ACI Structural Journal, vol. 102, no. 3, pp. 462-471, 2005.

[7] R. N. Swamy and K. I. Anand, "Structural behaviour of high strength concrete beams," Building Science, vol. 9, no. 2, pp. 131-141, 1974.

[8] S. Sarkar, O. Adwan, and J. L. Munday, "High strength concrete: an investigation of the flexural behaviour of high strength RC beams," Structural Engineer, vol. 75, no. 7, pp. 115-121, 1997.

[9] S. A. Ashour, "Effect of compressive strength and tensile reinforcement ratio on flexural behavior of high-strength concrete beams," Engineering Structures, vol. 22, no. 5, pp. 413-423, 2000.

[10] ACI Committee, "Building Code Requirements for Reinforced Concrete (ACI 318-08)," American Concrete Institute, 2008.

[11] ACI Committee, "Standard Practice for Selecting Proportions for Normal, Heavyweight, and Mass Concrete (ACI 211.191)," American Concrete Institute, 1991.

[12] N. Raju and R. Pranesh, Reinforced Concrete Design: Principles and Practice, New Age International Limited, New Delhi, India, 2003.

[13] W. Koyangi, K. Rokugo, and Y. Uchida, "Mechanical properties of concrete deteriorated by alkali-aggregate reaction under various reinforcement ratios," in Proceedings of the 9th International Conference on Alkali-Aggregate Reaction, pp. 556-563, London, UK, 1992. 
[14] L. F. Bernardo and S. M. Lopes, "Neutral axis depth versus flexural ductility in high-strength concrete beams," Journal of Structural Engineering, vol. 130, no. 3, pp. 452-459, 2004.

[15] P. S. Kumar, M. A. Mannan, V. J. Kurian, and H. Achuytha, "Investigation on the flexural behaviour of high-performance reinforced concrete beams using sandstone aggregates," Building and Environment, vol. 42, no. 7, pp. 2622-2629, 2007.

[16] A. Shuaib and R. Barker, "Flexural behavior of reinforced high-strength lightweight concrete beams," ACI Structural Journal, vol. 88, no. 1, pp. 69-77, 1991. 

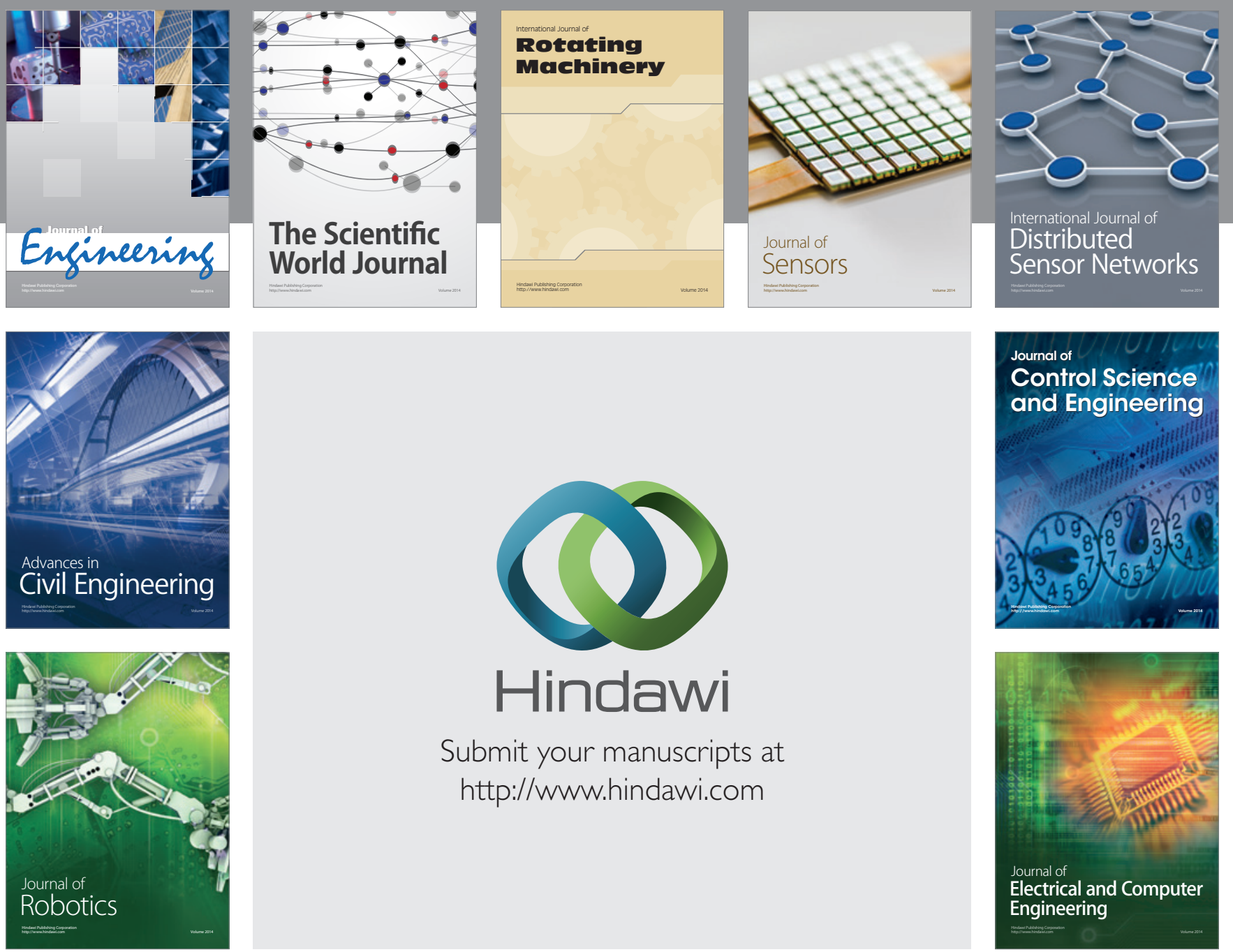

Submit your manuscripts at

http://www.hindawi.com
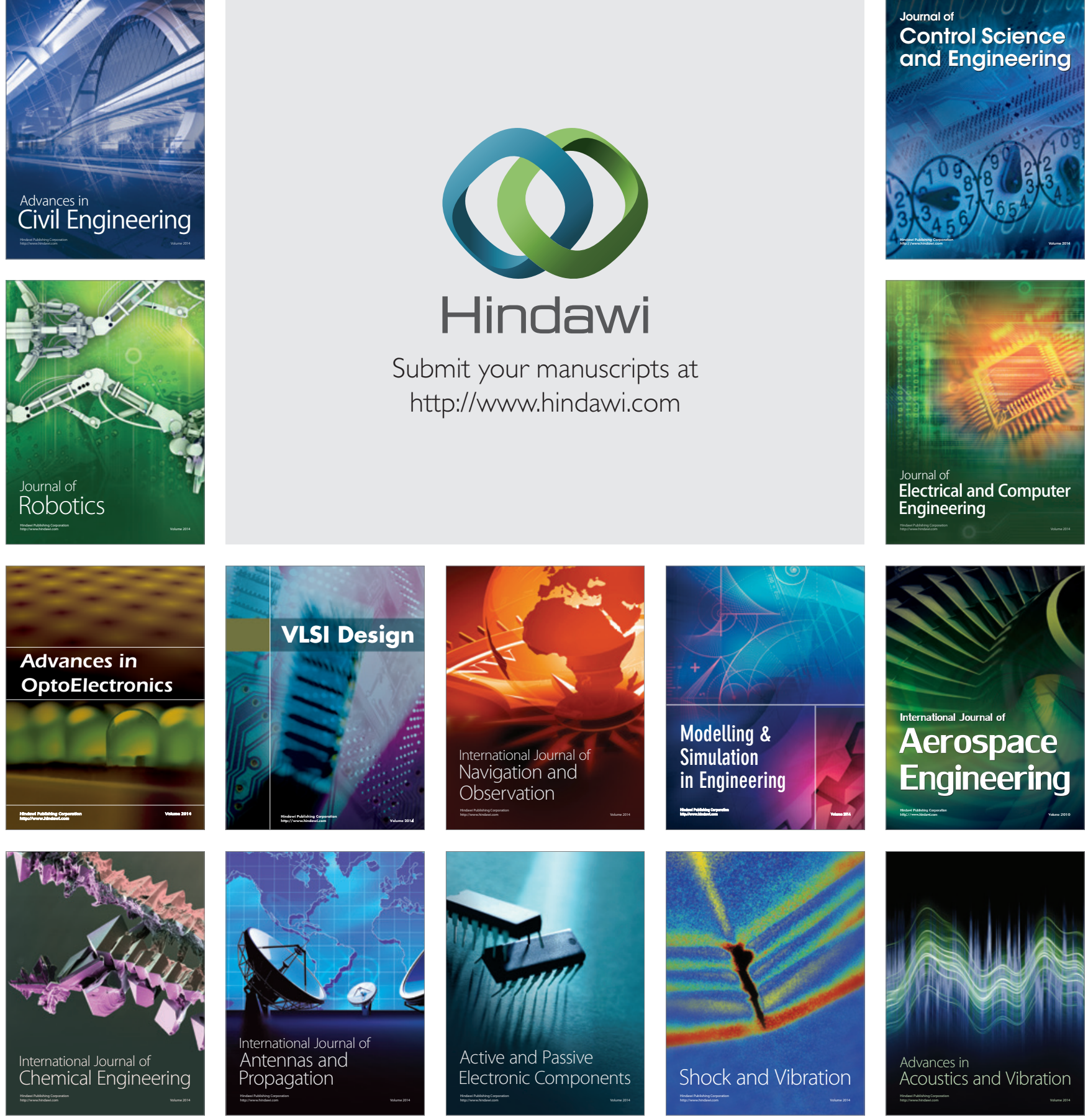